\title{
HIPOTERMIA TERAPÊUTICA: EFEITOS ADVERSOS, COMPLICAÇÕES E CUIDADOS DE ENFERMAGEM
}

Lisiane van Ommeren Corrêa ${ }^{1}$, Rosemary Silva da Silveira ${ }^{2}$, Joel Rolim Mancia ${ }^{3}$, Natália Lopes Correa², Ismael Moron de Souza Reinhardt' Valéria Lerch Lunardi Rosane Mortari Ciconet ${ }^{3}$

Objetivo: conhecer os efeitos adversos e complicações vivenciadas pela equipe de saúde e conhecer os cuidados de enfermagem realizados durante a aplicação da hipotermia terapêutica. Metodologia: pesquisa com abordagem qualitativa, realizada em 2014, mediante entrevistas semiestruturadas com trabalhadores da saúde de Unidades de Terapia Intensiva de dois hospitais do extremo sul do Brasil, em que é aplicada a hipotermia terapêutica pós-parada cardiorrespiratória. Utilizouse a análise textual discursiva. Resultados: Dentre os efeitos adversos, foram destacados tremores, bradicardia, hipotensão e complicações como queimaduras de pele. Os cuidados de enfermagem direcionam-se aos cuidados com a pele e extremidades, uso do gelo, sedação e conforto. Conclusão: a hipotermia terapêutica é possível de ser aplicada, na realidade das instituições pesquisadas, de maneira segura, eficaz e com baixo custo, fazendo-se relevante, entretanto, a realização de qualificação das equipes, a fim de esclarecer dúvidas e favorecer a adesão e os cuidados necessários de serem prestados.

Descritores: Hipotermia Induzida; Parada Cardiaca; Enfermagem.

\section{THERAPEUTIC HYPOTHERMIA : ADVERSE EFFECTS, COMPLICATIONS AND NURSING CARE.}

Summary: to know the adverse effects and complications experienced by the health team and cognize the nursing care performed during the application of therapeutic hypothermia. Methodology: this research was developed with a qualitative approach, conducted in 2014, with semi-structured interviews with health workers from Intensive Care Units of two hospitals in the extreme south of Brazil, which applied therapeutic hypothermia after cardiorespiratory arrest. The textual discursive analysis was used. Results: Adverse effects included tremors, bradycardia, hypotension and complications such as skin burns. Nursing care is mainly dedicated to skin and extremity care, ice use, sedation and comfort. Conclusion: Therapeutic hypothermia is possible to be applied, in the reality of the researched institutions, in a safe, effective and with low cost way, however, it is necessary to carry out the qualification of the teams, in order to clarify doubts and favor adherence and the necessary care to be provided.

Descriptors: Induced Hypothermia; Heart Arrest; Nursing.

\section{HIPOTERMIA TERAPÉUTICA: EFECTOS ADVERSOS, COMPLICACIONES Y CUIDADOS DE ENFERMERÍA.}

Resumen: conocer los efectos adversos y complicaciones vivenciadas por el equipo de salud y conocer los cuidados de enfermería realizados durante la aplicación de la hipotermia terapéutica. Metodología: investigación con abordaje cualitativo, realizada en 2014, con entrevistas semiestructuradas con trabajadores de la salud de Unidades de Terapia Intensiva de dos hospitales del extremo sur de Brasil, en que se aplica la hipotermia terapéutica post-parada cardiorrespiratoria. Se utilizó el análisis textual discursivo. Resultados: Entre los efectos adversos, fueron destacados temblores, bradicardia, hipotensión y complicaciones como quemaduras de piel. Los cuidados de enfermería se dirigen a los cuidados con la piel y extremidades, uso del hielo, sedación y confort. Conclusión: la hipotermia terapéutica es posible de ser aplicada, en la realidad de las instituciones investigadas, de manera segura, eficaz y con bajo costo, haciéndose necesaria, sin embargo, la realización de calificación de los equipos, a fin de aclarar dudas y favorecer la adhesión y los cuidados necesarios para ser prestados.

Descriptores: Hipotermia Inducida; Paro Cardíaco; Enfermería. 


\section{INTRODUÇÃO}

A parada cardiorrespiratória (PCR) é uma condição súbita em que ocorre a interrupção abrupta do fluxo sanguíneo e do transporte de oxigênio para os órgãos vitais, como o coração, rins, fígado, pulmões e cérebro, reduzindo a capacidade de gerar um fluxo mínimo que garanta a integridade celular e tecidual, influenciando a relação do gasto cardíaco, resistência vascular sistêmica e pressão arterial, com risco de lesões isquêmicas, dentre outras sequelas ${ }^{(1)}$.

Nesse cenário, a hipotermia terapêutica (HT) mostrase como alternativa para reduzir as sequelas oriundas da PCR, melhorando a qualidade de vida dos sobreviventes após manobras de reanimação, pois, em decorrência da parada, são desencadeadas duas ondas de morte de células neuronais, por necrose ou por apoptose. A HT torna-se neuroprotetora, uma vez que atenua sinais apoptóticos (tais como a liberação do citocromo C) e ativa mecanismos antiapoptóticos, aumentando a expressão da proteína p53, que promove a reparação celular após isquemia focal. Assim, seus benefícios são evidenciados pelos níveis reduzidos de enolase, um marcador da morte de neurônios ${ }^{(2.3)}$.

Além disso, a HT atenua e/ou atrasa a despolarização axonal causada pela depreciação da adenosina trifosfato e a consequente liberação de glutamato no espaço extracelular, reduzindo a excitotoxicidade ${ }^{2}$. Não obstante, tem a capacidade de diminuir a pressão intracraniana e de reduzir a permeabilidade vascular, minimizando o aparecimento de edema cerebral e prevenindo a ruptura da barreira hematoencefálica ${ }^{(3)}$.

A American Heart Association destacou que pacientes adultos comatosos, com retorno circulatório espontâneo após PCR, devem ser submetidos ao controle direcionado de temperatura entre 32 e $36 \circ \mathrm{C}$, a qual deve ser mantida constantemente durante pelo menos 24 horas $^{(4)}$. Apesar de seus efeitos neuroprotetores, a aplicação da HT mostra-se um processo complexo que desencadeia efeitos fisiológicos nos sistemas circulatório e cardiovascular ${ }^{(5)}$, urinário, imunológico e, também, no gastrointestinal( ${ }^{(6)}$.

De acordo com o nível de hipotermia atingido, podem ocorrer, também, sinais e sintomas oriundos do tratamento; quando o paciente é resfriado a temperatura de 36 으, observa-se aumento do metabolismo necessário para aquecer - corpo, pele pálida, entorpecimento, músculos tensos, fadiga e sinais de fraqueza. Entre $34 \circ \mathrm{C}$ e $35 \circ \mathrm{C}$, observa-se tremores intensos descontrolados, dor e desconforto devido ao frio, produzindo aumento da atividade muscular, elevando a taxa metabólica em quatro vezes, o que envolve uma maior produção de calor e o aumento no consumo de oxigênio(2). Nos valores entre 31 으 e 33 으, os tremores diminuem ou cessam, os músculos enrijecem, há confusão mental, apatia, discurso diminuido e arrastado, respiração lenta e superficial e sonolência. Abaixo de 31으, observa-se pele fria, pupilas dilatadas, fraqueza extrema, exaustão, perda gradual da consciência, parada respiratória progressiva e $\operatorname{arritmias}^{(2,7)}$

Diante do exposto, torna-se evidente a necessidade de que a enfermagem mantenha vigilância constante do paciente submetido à hipotermia terapêutica, durante as 24 horas do dia, executando cuidados especificos para obtenção da melhora clínica, uma vez que, em cada uma das fases da HT, são exigidos cuidados individualizados relacionados à complexidade clínica do paciente submetido a essa terapêutica ${ }^{(b)}$. Para isso, é necessária uma equipe devidamente qualificada e comprometida, a fim de identificar qualquer tipo de variação indevida na temperatura, bem como de efeitos fisiológicos e colaterais provenientes da aplicação da HT que possam interferir no bom prognóstico neurológico.

Paraobter-seum bom prognóstico, énecessária constante avaliação dos efeitos dessa terapêutica, uma conduta baseada em evidências e, ainda, padronização das ações de cada profissional envolvido no processo da hipotermia terapêutica, a fim de alcançar resultado eficaz. No entanto, apesar de demonstrar resultados positivos e promissores, a utilização da HT ainda é limitada a poucos hospitais, pois seus principais impedimentos são: a ausência de experiência com o arrefecimento, falta de conhecimento acerca dos benefícios e efeitos positivos da $\mathrm{HT}$, desconhecimento das diretrizes e dimensionamento de pessoal inadequado ${ }^{(8)}$.

Assim, esse estudo teve o intuito de conhecer os efeitos adversos e complicações vivenciadas pela equipe de saúde $e$ conhecer os cuidados de enfermagem realizados durante a aplicação da HT.

\section{METODOLOGIA}

Esta pesquisa desenvolveu-se numa abordagem qualitativa, em duas Unidades de Terapia Intensiva (UTI) de dois hospitais do extremo sul do Rio Grande do Sul, nas quais a HT foi aplicada. A UTI A caracteriza-se como uma instituição filantrópica, de alta complexidade nível I, especializada no tratamento cardiológico, onde são realizados estudos e tratamentos hemodinâmicos e cirurgias cardiovasculares: e a UTI B trata-se de um hospital universitário de alta complexidade, especializado em diversas áreas.

A coleta de dados ocorreu em 2014, mediante entrevistas semiestruturadas, gravadas com aparelho digital, focalizando questões relacionadas à HT, como: vivências, implementação de protocolos na unidade, preparo dos trabalhadores, intercorrências e seu enfrentamento, cuidados adotados com os pacientes, dentre outros.

Adotou-se, como critérios de inclusão, ser funcionário do local há no mínimo quatro meses e ter atuado na aplicação da 
HT pós PCR em pelo menos um paciente. Assim, participaram do estudo 14 profissionais da instituição "A" e 12 profissionais da instituição “B”, compreendendo 14 técnicos de Enfermagem, 7 enfermeiros e 5 médicos. Foram identificados pela sigla $A$ ou B, pela identificação de trabalhadores $(T)$ e os respectivos números ordinais (A-Tl e B-T15, por exemplo), conforme a ordem das entrevistas. Os dados das entrevistas foram submetidos à análise textual discursiva, proposta por Moraes e Galiazzi(9), construindo-se as seguintes categorias: Efeitos adversos e complicações vivenciados pela equipe de saúde; Cuidados de enfermagem durante a aplicação da hipotermia terapêutica.

Obteve-se a aprovação dos respectivos Comitês de Ética em Pesquisa mediante parecer no 140/2014 e no 016/2014.

\section{RESULTADOS}

Efeitos adversos e complicações vivenciadas pela equipe de saúde

Como efeitos adversos, foram destacadas a presença de tremores e a ocorrência de alterações relacionadas ao sistema cardiovascular, como: tremores (A-Tl, A-T4), hipotensão (A-Tl) e bradicardia (A-Tl, A-T4, A-Tll, A-Tl2, A-Tl4, B-Tl5, B-T16): "No início ela tremeu, mas foi administrado bloqueador neuromuscular, o atracúrio [...] Aprofundou a sedação e aumentou a questão do relaxante, em seguida, ela parou de tremer." (B-T18); "O paciente ficou muito bradicárdico, foi preciso interromper." (B-T25).

Dentre as complicações, foi evidenciado o alcance de temperaturas abaixo do preconizado na aplicação da HT e queimaduras provocadas pelo resfriamento com gelo na pele dos pacientes: "Hipotermia excessiva. Na nossa primeira paciente colocamos gelo até $32 \circ \mathrm{C}$, aí com $32 \circ \mathrm{C}$ tiramos o gelo, quando fomos ver ela estava com 30 e poucos graus." (A-T14); "Uma senhora que tivemos no isolamento foi a 28 드 de temperatura." (B-T15); "Uma das primeiras pacientes ficou bem vermelhinha, queimada do gelo." (B-T15); "Já aconteceu de um paciente ser queimado, ele ficou com a marca na pele." (B-T24).

Cuidados de enfermagem durante a aplicação da hipotermia terapêutica

Quanto aos cuidados de enfermagem realizados para evitar a queimadura da pele durante a aplicação da HT, foram destacados: "Cuidar para não queimar a pele, coloca-se o gelo por cima de lençol [...] para não ficar em contato direto com a pele." (B-T16); "Cuidar das extremidades, porque como vai resfriar muito, deve-se procurar deixar o gelo mais na parte central; avaliar periodicamente as extremidades como mãos e pés para não fazer gangrena" (B-T24)

Os participantes destacaram os cuidados de enfermagem que necessitam ser efetivados para favorecer a aplicação da hipotermia terapêutica, tais como cuidados com o material que será utilizado na indução, avaliação e monitorização frequente do paciente, bem como, a realização de procedimentos para assegurar as funções fisiológicas vitais: "Nós preparamos o paciente, preparamos a sedação e colocamos o termômetro esofágico [...] solicitamos a compra do gelo." (B-T15); “É passada sonda vesical, sonda nasogástrica e o termômetro esofágico [...] É instalada pressão arterial média (PAM)." (AT1); “É controlada a temperatura através do termômetro esofágico para verificar a temperatura interna de órgãos." (B-T21); "O BIS mostra a atividade cerebral para manter o paciente sedado numa atividade mínima necessária para que se tenha benefício." (A-T8); “É realizada a oximetria [...] ou se controla por gasometria porque é mais fidedigna do que a digital." (B-T24)

Dentre os cuidados de enfermagem realizados para priorizar a manutenção do bem-estar e conforto dos pacientes, foram destacadas a observação das condições de sedação, da sensibilidade para a dor, bem como a ausência da administração da dieta e o manuseio desnecessário do paciente: "A gente não toca neles, só se tiver que aspirar, fazer alguma medicação EV ou subcutânea, mas movimentar, mudar de decúbito, trocar lençol, essas coisas a gente não mexe neles." (A-Tll); "Observar se o paciente está bem sedado, se não estiver, observar FC, se existe algum vestígio de dor [...] se o paciente vai reagir ou qualquer outra coisa que faça com que ele ainda esteja desconfortável [...] Sempre verificando se ele não acorda em nenhum momento [...] Temos que estar sempre olhando para o paciente, vendo se ele terá algum movimento, algum reflexo, alguma coisa." (B-T18); "Nessas 24 horas, não é passada dieta." (B-T15).

\section{DISCUSSÃO}

A presença de tremores foi um dos efeitos adversos destacados pelos participantes. A preocupação com esse efeito está relacionada ao fato de o tremor promover o aumento da atividade muscular, elevando a taxa metabólica em quatro vezes, o que envolve uma maior produção de calor e aumento no consumo de oxigênio, retardando o alcance da temperatura alvo(2). No entanto, a prevenção e manejo dos tremores só foram identificados na instituição "A", a qual padroniza a utilização de bloqueador neuromuscular, com orientação de reavaliação da sua utilização após 12 horas de hipotermia.

Pode-se constatar que, nas instituições pesquisadas, não foram utilizados os métodos não farmacológicos tais como: aquecimento local das mãos, pés e face dos pacientes ${ }^{(10)}$. No que tange aos efeitos cardiovasculares, a bradicardia foi o mais comumente citado pelos participantes, sendo evidenciada principalmente na fase da indução da HT. A ocorrência de 
bradicardia, isoladamente, assim como a hipotensão, não produzem riscos ao paciente, podendo ser manejadas. Contudo, quando associadas, podem se tornar um potencial para desencadear PCR. Apesar de os valores da frequência cardiaca (FC) alterarem-se com a mudança da temperatura e dos possíveis efeitos adversos sobre o ritmo cardíaco, a HT pode até ter um efeito positivo na contratilidade cardiaca ${ }^{(10,11)}$.

Já, a hipotermia excessiva consiste numa complicação com potencial para uma intercorrência, pois ao alcançar temperaturas abaixo de $28 \circ \mathrm{C}$, a chance de ocorrer uma bradicardia grave é maior; nessas condições de resfriamento, o miocárdio torna-se sensível a manipulações mecânicas, desencadeando arritmias severas, bem como, dificultando sua reversão ${ }^{12}$. Nesse sentido, as chances de ocorrer uma PCR em fibrilação ventricular são maiores, dado que, nessas condições de resfriamento, existe o risco de rigidez muscular com perda dos reflexos de estimulação da pele e dos vasos capilares da córnea, conjuntiva, reflexos tendinosos profundos, além da ausência do pulso e respiração(13).

Quanto à ocorrência de queimaduras durante a aplicação do gelo, foi evidenciado que a HT causa vasoconstrição periférica, que pode levar a uma ruptura da pele, situação que exige avaliação da equipe de enfermagem com regularidade, para detectar sua ocorrência precocemente ${ }^{(14)}$. A equipe de enfermagem demonstra grande preocupação com os cuidados para evitar queimaduras de pele, utilizando, como estratégia, a colocação do gelo envolvido em lençóis, toalhas, compressas ou mesmo em sacos plásticos para que não ocorra contato direto do gelo com a pele. Além disso, a equipe de enfermagem faz avaliações frequentes da pele e das extremidades devido ao fato de o gelo fazer vasoconstrição. Associado a isso, o uso de vasoconstritor como a noradrenalina pode potencializar o risco da presença de cianose e até gangrena nas extremidades. Sendo assim, um rodízio dos locais onde foi aplicado o gelo, o uso de luvas e botas comalgodão ortopédico para proteger respectivamente as mãos e os pés, tornam-se cuidados fundamentais ${ }^{(14)}$.

A realização dos procedimentos de competência do enfermeiro, tais como a passagem de sonda vesical, de sonda nasogástrica, do termômetro esofágico, bem como o preparo da sedação, são fundamentais para monitorar e manter as funções vitais e devem ser realizados o mais cedo possivel, uma vez que a HT desencadeia efeitos adversos importantes que podem comprometer o prognóstico do paciente. Foi constatado, ainda, que a instalação de pressão arterial média (PAM) é realizada rotineiramente pela equipe da instituição "A", uma vez que a verificação de pressão arterial manual e a verificação da saturação de oxigênio, através da oximetria, tornam-se praticamente inviáveis em decorrência da vasoconstrição periférica ocasionada pela hipotermia. Por esse motivo, o cateter arterial necessita ser colocado ainda na fase da indução(10)

A equipe de enfermagem tem como foco de seu fazer o cuidado ao paciente e assume, durante o período de 24 horas, a responsabilidade direta no controle de sinais vitais, monitorização, administração de medicamentos, exame físico e cuidados gerais durante as fases de indução, manutenção e reaquecimento, já que esses pacientes passam a maior parte do tratamento sedados ${ }^{(15)}$. Além desses cuidados, a equipe de enfermagem assume a assistência direta ao paciente, promovendo conforto, privacidade, evitando condutas iatrogênicas, como lesões de pele e de alterações bruscas da temperatura e dos sinais vitais ${ }^{15}$. O profissional de enfermagem deve atentar para alguns cuidados que não podem ser realizados durante a aplicação da HT, tais como a instalação de dieta, pois a HT reduz a motilidade intestinal, levando a uma demora no esvaziamento gástrico, o que contraindica a administração de qualquer tipo de dieta durante as fases da $\mathrm{HT}^{(7)}$

Dentre os cuidados de enfermagem destacados pelos trabalhadores para favorecer o processo de aplicação da $H T$, os enfermeiros salientam a necessidade de realizar uma observação constante do paciente e do seu nivel de sedação, o qual também foi relatado no estudo de Silva e Kelly, uma vez que a sedação leva o paciente a não ter percepção do desconforto relativo ao procedimento e também das consequências que podem ter surgido em decorrência da $\mathrm{PCR}^{(16)}$.

Destaca-se que esse estudo teve, como limitações, sua realização em apenas dois hospitais do extremo sul do Brasil, com um número pequeno de pacientes submetidos à terapêutica em questão, Outra limitação está relacionada à existência de poucos estudos abordando a terapêutica do ponto de vista da enfermagem, demonstrando a necessidade do prosseguimento de pesquisas nessa temática.

\section{CONCLUSÃO}

Verificou-se que os efeitos adversos da aplicação da HT desencadearam a ocorrência de tremores, bradicardia e hipotensão e de complicações como hipotermia excessiva e queimaduras de pele. Quanto aos cuidados de enfermagem, foi possivel constatar os cuidados com a pele e extremidades na tentativa de evitar a ocorrência de queimaduras e gangrena. Constatou-se o quanto é necessária a vigilância constante durante o uso do gelo, bem como o preparo do material, inclusive no que se refere à aquisição do gelo. Os enfermeiros destacaram a importância da monitorização constante do paciente e da realização de procedimentos como sondagem vesical, sondagem nasogástrica, instalação de termômetro esofágico e de pressão arterial média para promover a 
observação cuidadosa, prevenir complicações e desenvolver o raciocínio clínico necessário para o planejamento dos cuidados ao paciente durante a aplicação da HT. Pode-se constatar que a restrição da dieta é necessária, uma vez que a hipotermia causa efeitos adversos relacionados ao sistema gastrointestinal. Além disso, a avaliação do nível de sedação dos pacientes é fundamental para evitar desconfortos relacionados ao procedimento.

Quanto aos cuidados de enfermagem, foi possivel identificar a realização de cuidados com a pele e extremidades para evitar queimaduras e gangrena decorrentes da vasoconstrição. Identificou-se, também, a necessidade de manter o bem-estar e o conforto do paciente, evitar a movimentação desnecessária do paciente e a mudança de decúbito.
Considera-se que a HT é viável de ser aplicada (na realidade dos hospitais pesquisados) de maneira segura, eficaz e de baixo custo, fazendo-se relevante, entretanto, a realização de qualificação das equipes, a fim de esclarecer dúvidas e favorecer a adesão e os cuidados necessários de serem prestados. Esse estudo poderá contribuir com outros profissionais de saúde que desejam iniciar o desenvolvimento da HT, uma vez que os resultados obtidos poderão servir de estímulo e referência para trabalhos que envolvam a temática abordada.

\section{REFERÊNCIAS}

1. Escobar J. Fisiopatologia del paro cardiorrespiratorio. Fisiologia de la reanimación cardiopulmonar. Rev Chil Anest. 2012; 41(1): 18-22.

2. Nunnally ME, Jaeschke R, Bellingan GJ, Lacroix J, Mourvillier B, Rodriguez-Vega GM, et al. Targeted temperature management in critical care: a report and recommendations from five professional societies. Crit Care Med. 2011; 39(5): 1113-25.

3. Garcia GG, Pérez-Saad H. Hipotermia como alternativa terapéutica. 16 de Abril. 2017; 56(264): 64-72. Avaliable from: http:// www.medigraphic.com/pdfs/abril/abr-2017/abr17264e.pdf

4. American Heart Association. Atualização das diretrizes de RCP e ACE. Dallas, 2015; 36p.

5. Rodrigues JHS, Faico Filho KS, Givisiez, BS, Silva IF, Ulhôa MA, et al. Beneficios na prevenção de lesão neuronal pós-parada cardiorrespiratória (PCR) na hipotermia terapêutica: breve revisão. Revista Eletrônica Gestão \& Saúde. 2015; 06(2): 1774-85.

6. Amaral GG, Maciel MFC, Batista JJ. Diagnósticos e intervenções de enfermagem frente às complicações da hipotermia induzida pós-parada cardiorrespiratória: revisão integrativa da literatura. Conexão Ci, 2017

7. Viana RAPP, Torre M. Enfermagem em Terapia Intensiva: Praticas Integrativas. Barueri, PS: Manole, 2017.

8. Beccaria LM, Finco BF, Rodrigues IJ, Cesarino CB. Hipotermia terapêutica após ressuscitação cardiorrespiratória em unidade coronária: concepção da equipe multiprofissional. Arq. Ciênc. Saúde. 2014; 22(2):107-11.
9. Moraes R, Galiazzi MDC. Análise Textual Discursiva. Ijui, 2011.

10. Costa DM. Hipotermia: utilização em doentes pós-paragem cardiaca. [TESE] Coimbra, 2015.

11. Correia BMRN. Sindrome pós-paragem cardiorrespiratória: fisiopatologia, tratamento e importância do controlo da temperatura. [TESE] Lisboa, 2017.

12. Prado SM, Magalhães CD, Rodrigues AC, Tajima SH, Oliveira PE, Egawa FH et al. Hipotermia neuroprotetora tardia. Rev Soc Bras Clin Med. 2017; 15(2):120-3.

13. Souza JE. Hipotermia terapêutica pós reanimação cardiorrespiratória: uma revisão bibliográfica. São Paulo: Revista Recien. 2013; 3(8):25-35

14. Bucher L, Buruschkin R, Kenyon DM, Stenton K, Treseder S. Improving outcomes with therapeutic hypothermia. Dimens Crit Care Nurs, 2013; 32(3): 147-51.

15. Waldrigues MC, Wagner BV, Mercês NNA, Perly T, Almeida EA, Caveião C. Complica-ções da hipotermia terapêutica: diagnósticos e intervenções de enfermagem $\mathrm{J}$. res.: fundam. care. 2014; 6(4):1666-76. Avaliable from: http://www.redalyc.org/ html/5057/505750770028/

16. Silva EM, Kelly LN. A hipotermia terapêutica na recuperação de pacientes pós parada car-diorrespiratória. Carpe Diem: Revista Cultural e Cientifica do UNIFACEX. 2017; 15(1). 